\title{
Characterization of Immune Responses to Mycobacterium tuberculosis Rv2041c Protein
}

\author{
Su-Young Kim ${ }^{1}$, A-Rum Shin ${ }^{2,4}$, Byung-Soo Lee,, ${ }^{2,4}$ Hwa-Jung Kim², Bo Young Jeon ${ }^{5}$, \\ Sang-Nae Cho ${ }^{5}$, Jeong-Kyu Park ${ }^{2,3 *}$ and Sung Jae Shin ${ }^{2,44^{\dagger}}$ \\ ${ }^{1}$ Division of Pulmonary and Critical Care Medicine, Department of Medicine, Samsung Medical Center, \\ Sungkyunkwan University School of Medicine, Seoul, Korea; ${ }^{2}$ Department of Microbiology, \\ ${ }^{3}$ Cancer Research Institute, ${ }^{4}$ Infectious Signaling Network Research Center, College of Medicine, \\ Chungnam National University, Daejeon, Korea; ${ }^{5}$ Department of Microbiology and Brain \\ Korea 21 Project for Medical Science, Yonsei Univeristy College of Medicine, Seoul, Korea
}

\begin{abstract}
Tuberculosis, which is caused by Mycobacterium tuberculosis (M. tb), is one of the most important infectious diseases in the world. Although many functional studies have been conducted on $M$. tb proteins in the post-genomic era, little is known about the function of many proteins expressed specifically during latency. Previously, we reported that $R v 2041 c$ from M. tb H37Rv is highly expressed under conditions of low $\mathrm{pH}$ and hypoxia, which represent the in vitro mimicry of latent tuberculosis. In the present study, increased expression levels of Rv2041c under hypoxia and low $\mathrm{pH}$ in vitro culture was confirmed by RT-PCR. Interestingly, Rv2041c showed significantly increased expression among genes of the same operon and genes belonging to the same functional group. Finally, the immune responses elicited by the recombinant (r) Rv2041c protein were investigated using ex vivo and in vivo models of $M$. tb infection. A significantly high level of pro-inflammatory cytokines such as TNF- $\alpha$, IL-6, and IL-12p40 was detected in a dose-dependent manner by treatment of murine bone marrow-derived macrophages with rRv2041c protein. In addition, IFN- $\gamma$ and TNF- $\alpha$ secretion increased after stimulation with purified Rv2041c protein to lymphocytes from latent and active TB mice in a modified Cornell model. In conclusion, our findings suggest that Rv2041c is a new T-cell antigen and could be a potential vaccine candidate against $M$. tb infection by inducing a strong cellular immune response.
\end{abstract}

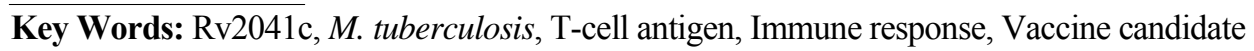

\section{INTRODUCTION}

Tuberculosis (TB) causes more than 2 million deaths

Received: August 5, 2009/ Revised: September 5, 2009,

Accepted: September 9, 2009

${ }^{*}$ Corresponding author: Jeong-Kyu Park. Department of Microbiology, College of Medicine, Chungnam National University, Daejeon 301-747,

Korea.

Phone: +82-42-580-8244, Fax: +82-42-585-3686,

e-mail: jekpark@cnu.ac.kr

${ }^{\dagger}$ Co-corresponding author: Sung Jae Shin. Department of Microbiology, College of Medicine, Chungnam National University, Daejeon 301-747, Korea.

Phone: +82-42-580-8246, Fax: +82-42-585-3686,

e-mail: sjshin@cnu.ac.kr

${ }^{* *}$ This study was supported by a grant of the Korea Healthcare technology R\&D Project, Ministry for Health, Welfare \& Family Affairs, Republic of Korea (A084342). every year (1). The ability of Mycobacterium tuberculosis $(M . t b)$ to persist in the host for long periods of time causes long-term disease (2). The chronic nature of the disease is likely due to the bacterium needing to adapt to a continually changing host environment, severely complicating any attempts to identify better therapeutics or diagnostics for this disease (3).

Although drug-susceptible TB can be treated successfully with a 6-month regimen involving three of four drugs (WHO DOTS strategy, $>95 \%$ cure rate), the combined challenges of timely diagnosis, socioeconomic factors in TB endemic areas, and the fact that bacterial clearance requires many months of treatment have prevented the successful global control of TB (4). The only current Bacillus 
Calmette-Guérin (BCG) vaccine, the most widely used in the world, is not completely protective. BCG is ineffective in individuals pre-sensitized by exposure to environmental mycobacteria prior to vaccination or $M$. tb infection $(5,6)$. In addition, BCG is a live vaccine and the development of protective immunity after vaccination appears to require $\mathrm{BCG}$ replication in the host, which can be prevented by a pre-existing immune response that can cross-react with BCG (7). Therefore, a novel and efficacious vaccine to replace BCG is needed urgently to control and eliminate TB.

Progress in mycobacterial proteomics, functional genomics, and recombinant biotechnology to produce and purify mycobacterial proteins might lead to the development of vaccines from putative candidates (8). However, little is known about the actual functions of many proteins from $M$. $t b$ or the proteins induced in the host post-infection. For this reason, many studies have been conducted to find the proteins expressed specifically during $M$. $t b$ infection using in vitro dormancy, ex vivo macrophage, and in vivo animal models. In the screening of antigens for the development of a TB vaccine or diagnosis, IFN- $\gamma$, and TNF- $\alpha$ inducing proteins are also very considerable candidates.

Several studies have reported on the genes and proteins that are highly expressed in macrophages and in the in vitro dormancy state to discover vaccine candidates $(9 \sim 11)$. However, the contribution of these proteins to host immune responses must be evaluated following ex vivo and in vivo M. $t b$ infection models.

In a previous study, the $R v 2041 c$ of $M$. $t b \mathrm{H} 37 \mathrm{Rv}$ was found (by differential expression using a customized amplification library [DECAL]) to be specifically induced under acidic and hypoxic conditions similar to those in a phagocytosed environment (12), and may be important for survival in the host. Currently, the host immune response to Rv2041c of $M . t b \mathrm{H} 37 \mathrm{Rv}$ is not completely elucidated.

Rv2041c is thought to be a sugar-binding lipoprotein component of the ATP-binding cassette (ABC) sugar transport system. In total, $38 \mathrm{ABC}$ transporter proteins have been identified in $M$. $t b$, only four of which are assigned for a role in carbohydrate import (13). The four identified sugar importers are encoded by genes clustered in the following operons: Rv2041c-Rv2040c-Rv2039c-Rv2038c, ugpA-ugpE-ugpB-ugpC, sugC-sugB-sugA-lpqY, and uspAuspE-uspC. These consist of membrane spanning domains (MSDs), cytoplasmic nucleotide binding domains (NBDs), and extra-cytoplasmic substrate binding protein (SBP). Each of these four transporters is composed of one SBP (Rv2041c, UgpB, LpqY, or UspC).

This SBP is a membrane-bound lipoprotein and may act as an antigenic membrane-surface component in interactions with the host cell. Nearly half of the annotated $M$. $t b$ lipoproteins do not share conserved domains with proteins outside of the genus Mycobacterium and thus represent proteins unique to mycobacteria (14). Experimental data concerning mycobacterial lipoprotein function are rare.

Key immune factors controlling tuberculosis and the reactivation of infection include $\mathrm{T}$ cells and macrophages. After phagocytosis of $M$. $t b$ by macrophages, activated macrophages induce IL-12 and reactive nitrogen intermediates production and expression of costimulatory molecules. This, in turn, leads to the activation of $\mathrm{T}$ and NK cells and IFN- $\gamma$ and TNF- $\alpha$ production, thus linking the innate and adaptive immune responses, augmenting the microbicidal activity of the phagocytes. TNF- $\alpha$ and IFN- $\gamma$ play critical roles in protective immunity against mycobacterial infection and immunopathology (15). Therefore, the identification of mycobacterial antigens that preferentially induce these cytokines is critical to the development of new anti-TB vaccines.

The goal of this study was to investigate the significant induction of Rv2041c transcripts in $M$. tb growing in vitro and to assess the immune responses by cytokine production in macrophage infection as well as IFN- $\gamma$ and TNF- $\alpha$ increase in primed lymphocytes from $M$. $t b$-infected mouse. The improved knowledge of immunoreactive Rv2041c properties may be conducive to the development of an efficacious anti-tuberculosis vaccine.

\section{MATERIALS AND METHODS}

\section{Plasmid and vector construction}

The cloning vector plasmid $\mathrm{pGEM}^{\circledR}-\mathrm{T}$ Easy and 
expression vector $\mathrm{pET}-28 \mathrm{a}$ were purchased from Promega (Madison, WI, USA) and Novagen (Madison, WI, USA), respectively. The plasmid $\mathrm{pGEM}^{\circledR}-\mathrm{T}$ Easy and pET-28a contained an ampicillin and a kanamycin resistance marker, respectively. The expression vector contained a T7 promoter and a N-terminal $6 \times$ His-tag coding sequence.

\section{Expression and purification of the recombinant Rv2041c protein}

The Rv2041c was amplified by PCR from $M$. tb H37Rv genomic DNA and then cloned into the pET-28a. The correct construct was transformed into competent Escherichia coli BL21 cells. For the expression of the Rv2041c, transformed E. coli BL21 cells were grown overnight at $37^{\circ} \mathrm{C}$ in LuriaBertani (LB) medium containing $30 \mu \mathrm{g} / \mathrm{ml}$ kanamycin (Sigma, St. Louis, MO, USA). The culture was then inoculated into LB medium containing the same concentration of kanamycin and grown at $37^{\circ} \mathrm{C}$ until the optical density at $600 \mathrm{~nm}\left(\mathrm{OD}_{600}\right)$ reached to 0.6. Expression of the protein was induced by adding $1 \mathrm{mM}$ isopropyl $\beta$-D-thiogalactoside (IPTG; Bioneer, Daejeon, Korea), and the culture was grown at $25^{\circ} \mathrm{C}$ for an additional $4 \mathrm{~h}$. For preparative purification, induced $E$. coli BL21 cells from a 1-L culture grown under optimum conditions were harvested by centrifugation at $4000 \mathrm{~g}$ for $20 \mathrm{~min}$ at $4^{\circ} \mathrm{C}$. The cell pellet was stored at $-20{ }^{\circ} \mathrm{C}$.

The recombinant (r) Rv2041c protein was extracted after cell disruption by sonication. The rRv2041c containing Nterminal histidine tag was purified using Ni-nitrilotriacetic acid (NTA) resin (Qiagen, Chatsworth, CA, USA). The rRv2041c was dialyzed five times in $10 \mathrm{mM}$ phosphate buffered saline (PBS, pH 7.2) using a Slide-A-Lyzer Dialysis Cassette with a $3 \mathrm{kDa}$ molecular weight cut-off (Pierce, Rockford, IL, USA). After dialysis, endotoxin contamination was removed using Detoxi-Gel Affinity Pak Columns (Pierce). The rRv2041c protein was incubated with endotoxin removal resin for overnight to remove LPS and concentrated by Centricon (2,000 MW cut-off; Millipore, Billerica, MA, USA). In addition, endotoxin was assayed under endotoxin-free experimental conditions using a Limulus amebocyte lysate pyrogen kit (Biowhittaker,
Walkersville, MD, USA). The quantity of endotoxin in the rRv2041c was detected $\leq 0.01 \mathrm{ng} / \mathrm{mg}$. The final concentration of purified $\mathrm{rRv} 2041 \mathrm{c}$ protein was determined using a BCA protein assay kit (Pierce). The dialyzed protein was analyzed by SDS-PAGE with Coomassie brilliant blue staining.

\section{Cultivation of $M$. tuberculosis H37Rv under limited culture conditions}

M. $t b \mathrm{H} 37 \mathrm{Rv}$ was grown in minimal Sauton's medium as surface pellicles as previously described (16). The medium was then removed by filtration, and the bacterial cells were transferred to normal $(\mathrm{pH} 7.2)$ or mildly acidic $(\mathrm{pH}$ 6.0) $7 \mathrm{H} 9$ medium and cultured static for 8 days at $37^{\circ} \mathrm{C}$ in a $\mathrm{CO}_{2}$ incubator set at $21 \%$ or $13 \% \mathrm{O}_{2}$, or with $0 \% \mathrm{O}_{2}$ in an anaerobic jar (Oxoid, Cambridge, UK) containing anaerogen (Oxoid) and an anaerobic indicator (Oxoid); normal condition ( $\mathrm{pH} 7.2$ and $\left.21 \% \mathrm{O}_{2}\right)$, normal $\mathrm{pH}$ with hypoxia $(\mathrm{pH}$ 7.2 and $13 \% \mathrm{O}_{2}$ ), normal $\mathrm{pH}$ with anoxia $(\mathrm{pH} 7.2$ and $0 \%$ $\mathrm{O}_{2}$ ), mildly acidic $\mathrm{pH}$ with hypoxia ( $\mathrm{pH} 6.0$ and $13 \% \mathrm{O}_{2}$ ), and mildly acidic $\mathrm{pH}$ with anoxia $\left(\mathrm{pH} 6.0\right.$ and $\left.0 \% \mathrm{O}_{2}\right)$. The acidic media were buffered with $100 \mathrm{mM}$ morpholinepropanesulfonic acid (MOPS; Sigma) and adjusted to $\mathrm{pH}$ 6.0 .

\section{Extraction of RNA from M. tuberculosis H37Rv}

Total RNA from $M$. tb $\mathrm{H} 37 \mathrm{Rv}$ was isolated using a catrimox-14 RNA isolation kit (Takara, Shiga, Japan) according to the manufacturer's instructions, with a protocol as described previously (17). Bacterial cells were pelleted, resuspended in catrimox-14, and sonicated on ice. The cell lysate was vortexed for $1 \mathrm{~min}$ and left to allow micelle formation. The lysate was then centrifuged. The pellet was resuspended in guanidium solution (4 M guanidium isothiocyanate, $0.2 \mathrm{M}$ sodium acetate, $\mathrm{pH} 4.0$ ), and subjected to phenol/chloroform/isoamyl alcohol extraction. The aqueous layer was precipitated in isopropanol, washed with $70 \%$ ethanol, and air dried. The RNA pellet was resuspended in DEPC-treated water, and assessed by gel electrophoresis. 
Table 1. Primers used in RT-PCR

\begin{tabular}{|c|c|c|c|}
\hline Gene & & Primer sequence & Product size \\
\hline \multirow{2}{*}{ rрoв } & sense & 5'-CGAGTGCAAAGACAAGGACATG-3' & \multirow{2}{*}{$486 \mathrm{bp}$} \\
\hline & anti-sense & 5'-CGCAGCTTGCGGTAGATGTC-3' & \\
\hline \multirow{2}{*}{$\operatorname{lpq} Y$} & sense & 5'-GATTTGGTAAATAGCCCGCC-3' & \multirow{2}{*}{$255 \mathrm{bp}$} \\
\hline & anti-sense & 5'-AGCCACCGATTTGAGGATCT-3' & \\
\hline \multirow{2}{*}{ uspC } & sense & 5'-AGTGGCCGGCTAATGAAGAT-3' & \multirow{2}{*}{$191 \mathrm{bp}$} \\
\hline & anti-sense & 5'-CTCCATCGCAAGTTGTCCAC-3' & \\
\hline \multirow{2}{*}{ ugpB } & sense & 5'-GTCAACGCGCTCAAGTTCAT-3' & \multirow{2}{*}{$190 \mathrm{bp}$} \\
\hline & anti-sense & 5'-CGTAGTCTTGTGTCCGGGTG-3' & \\
\hline \multirow{2}{*}{$R v 2038 c$} & sense & 5'-ACGGTGTCACTGGGTGATTG-3' & \multirow{2}{*}{206 bp } \\
\hline & anti-sense & 5'-ATTGACTGGTCATTTCGCA-3' & \\
\hline \multirow{2}{*}{ Rv2039c } & sense & 5'-CGCGATACGTTGTTCGTCTT-3' & \multirow{2}{*}{$255 \mathrm{bp}$} \\
\hline & anti-sense & 5'-CAGCAGAATCCGCCAGTAGA-3' & \\
\hline \multirow{2}{*}{$R v 2040 c$} & sense & 5'-TTATCGTCAGCCTCGTCGTC-3' & \multirow{2}{*}{$205 \mathrm{bp}$} \\
\hline & anti-sense & 5'-GGTTCGATTAGCCATGGGAT-3' & \\
\hline \multirow{2}{*}{ Rv2041c } & sense & 5'-TATCCCGATATCAAGGTACG-3' & \multirow{2}{*}{$233 \mathrm{bp}$} \\
\hline & anti-sense & 5'-GTGAAAGTCTCATACAGGGC-3' & \\
\hline
\end{tabular}

\section{Semi-quantitative RT-PCR}

The first-strand cDNA was obtained from $1 \mu \mathrm{g}$ total RNA with reverse transcriptase and random primer at $42{ }^{\circ} \mathrm{C}$ for $60 \mathrm{~min}$. Reactions were stopped by heat inactivation for 5 min at $95^{\circ} \mathrm{C}$ and chilled on ice. Initially RT-PCR was carried out using primers for amplifying $r p o B$ to optimize the cDNA concentration. The PCR was carried out using $1 \mu \mathrm{l}$ of single-stranded cDNA for 30 cycles of 1 min denaturing at $95^{\circ} \mathrm{C}, 1 \mathrm{~min}$ annealing at $51^{\circ} \mathrm{C}$, and $1 \mathrm{~min}$ extension at $72^{\circ} \mathrm{C}$. Sequences of the specific oligonucleotide primers used for PCR amplification and the size of the predicted PCR products are shown in Table 1 . The PCR products were analyzed with $1 \%$ agarose gel electrophoresis and the intensity of each band was calculated using Quantity One software (Version 4.1.0; Bio-Rad, Hercules, CA, USA). All samples were compared to normal culture (oxygen pressure of $21 \%, \mathrm{pH} 7.2$; condition 1) and the gene expression level of this condition corresponds to 1 . The results were expressed as the fold induction relative to the control value of normal condition
Cytokine production in murine BMDMs by stimulation with Rv2041c protein

To determine the responses in macrophages by the stimulation with rRv2041c, murine bone marrow-derived macrophages (BMDMs) were used for ex vivo macrophage M. tuberculosis infection. Specific pathogen-free female C57BL/6 mice (Japan SLC, Shijuoka, Japan) at 5 6 weeks of age were used for the isolation of BMDMs. BMDMs were differentiated for 6 days in M-CSF-containing media, as described previously $(18,19)$. The culture medium consisted of DMEM that was supplemented with $20 \%$ L929 cell-conditioned medium (as a source of M-CSF), $10 \%$ heat-inactivated $\mathrm{FBS}, 1 \mathrm{mM}$ sodium pyruvate, $50 \mathrm{U} /$ $\mathrm{ml}$ penicillin, $50 \mu \mathrm{g} / \mathrm{ml}$ streptomycin, and $5 \times 10^{-5} \mathrm{M}$ 2-mercaptoethanol. The prepared BMDMs were cultured in DMEM medium in the presence of diverse concentration $(0.5,1,5 \mu \mathrm{g} / \mathrm{ml}$ ) of $\mathrm{rRv} 2041 \mathrm{c}$ and $1 \mu \mathrm{g} / \mathrm{ml}$ of LPS (as a positive control; Sigma) for $18 \mathrm{~h}$. Non-treated cells were used as a negative control. This experiment was conducted in triplicate and repeated 3 times. Culture supernatants were 


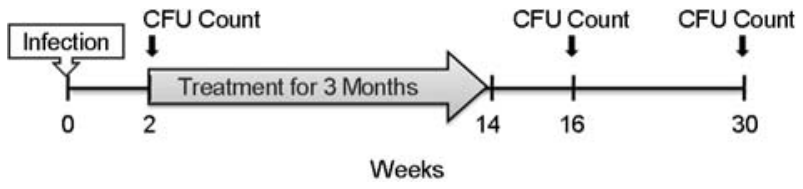

Figure 1. Experimental schedules for the animal models of latent and active TB. Mice were exposed to $M$. $t b$ H37Rv in the inhalation chamber of an airborne infection apparatus. Bacteria were counted 2 weeks after exposure. Mice were then treated with INH and PZA for 3 months, starting 2 weeks after aerosol infection. Bacterial counts were obtained from lung and spleen of mice at 2 and 16 weeks after the completion of 3 months of chemotherapy. The active TB mice in the Cornell model were obtained by natural reactivation.

then collected and frozen at $-80^{\circ} \mathrm{C}$ until ELISA analysis.

\section{Animal model in latent and active TB}

Specific pathogen-free female C57BL/6 mice at 5 6 weeks of age were purchased from Japan SLC, Inc. and maintained under barrier conditions in a BL-3 biohazard animal room at Yonsei University Medical Research Center. The animals were fed on a sterile commercial mouse diet and provided with water ad libitum. All animal experiments were done according to the regulation of Institutional Animal Care and Use Committee, Yonsei University Health System.

The Cornell model described by McCune et al. was employed with minor modification $(20,21)$ (Fig. 1). Briefly, mice were exposed to a predetermined dose (low-dose; 50 $\mathrm{CFU})$ of $M . t b \mathrm{H} 37 \mathrm{Rv}$ for $60 \mathrm{~min}$ in the inhalation chamber of an airborne infection apparatus (Glas-Col, Terre Haute, IN, USA). Bacteria were counted 2 weeks after exposure. Mice were then treated with INH at $25 \mathrm{mg} / \mathrm{kg} /$ day and PZA at $1000 \mathrm{mg} / \mathrm{kg} / \mathrm{day}$, in diet for 3 months, starting 2 weeks after aerosol infection. Bacterial counts were taken from the lungs and spleens of mice at 2 weeks after the completion of 3-month chemotherapy to confirm the clearance of cultivable organisms. At 18 weeks post-infection ( 2 weeks after completion of the 3-month treatment with $\mathrm{INH}$ and PZA), viable $M$. $t b$ in the lungs and spleens of mice was not found by culture on laboratory media. Bacteria were counted 30 weeks after infection, and approximately 75 and 50 viable $M$. $t b$ were found to have been delivered to the lungs and spleens, respectively. At this point of time, this established infection model represents latent infection. The active TB mice in the modified Cornell model were obtained by naturally reactivation.

\section{Preparation of lymphocytes from spleens in latent and active TB mice and stimulation with Rv2041c protein}

At 30 weeks post-infection and naturally reactivation after the completion of 3-month chemotherapy, mice were euthanized with $\mathrm{CO}_{2}$, and spleens were removed aseptically. Spleens were homogenized in $0.04 \%$ Tween 80 saline and lymphocytes were prepared from tissue suspension. Erythrocytes were lysed with a lysis buffer $(155 \mathrm{mM}$ ammonium chloride and $10 \mathrm{mM}$ potassium bicarbonate), and cells were washed. Splenocytes were plated at $2 \times 10^{5}$ cells per well and cultured in RPMI medium in the presence of the purified Rv2041c and concanavalin A (Con A; Sigma) at a concentration of $1 \mu \mathrm{g} / \mathrm{ml}$ for 1 or 4 days. The non-treated and Con A-treated cells were served as a negative and a positive control, respectively. Culture supernatants were then collected and frozen at $-80^{\circ} \mathrm{C}$ until ELISA analysis.

\section{Determination of cytokine concentration by ELISA}

Cytokine production (IFN- $\gamma$, TNF- $\alpha$, IL-6 and IL-12p40) was measured with commercial mouse enzyme-linked immunosorbent assay (ELISA) kits (BD Pharmingen, San Diego, CA, USA) following the procedure provided by the manufacturer. Cytokine concentrations in the samples were calculated using standard curves generated from recombinant cytokines, and the results were expressed in picograms per milliliter.

\section{RESULTS}

\section{Purification of the rRv2041c protein}

The rRv2041c protein containing a C-terminal histidine tag was purified using Ni-NTA resin. The purified protein displayed the expected molecular mass by SDS-PAGE analysis (Kim et al., submitted). The purified protein was dialyzed against PBS to remove the salts, followed by SDS-PAGE analysis to confirm that the dialyzed protein remained intact (Fig. 2). The small sized peptide bands are 
most probably derived from the degradation of recombinant protein. For subsequent experiments using rRv2041c protein, macrophage viability was tested by post-treatment with rRv2041c protein. There were no statistically significant differences in the percentage of dead cells in murine BMDM

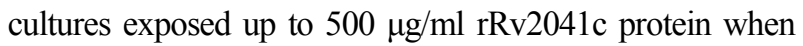
cell viability was assessed using a Cell Counting Kit-8 (Dojindo Laboratories, Kumamoto, Japan). This indicates that our rRv204c protein is not cytotoxic to BMDMs and does not contain significant amounts of endotoxin that would interfere at concentrations below $500 \mu \mathrm{g} / \mathrm{ml}$. Finally, the protein concentration was determined and the purified rRv2041c protein was used in the subsequent experiments.

Confirmation of the expression of Rv2041c at the transcriptional level in vitro by semi quantitative RTPCR

The Rv2041c of M. tb H37Rv was found (using differential expression and a customized amplification library [DECAL]) to be specifically induced under acidic and

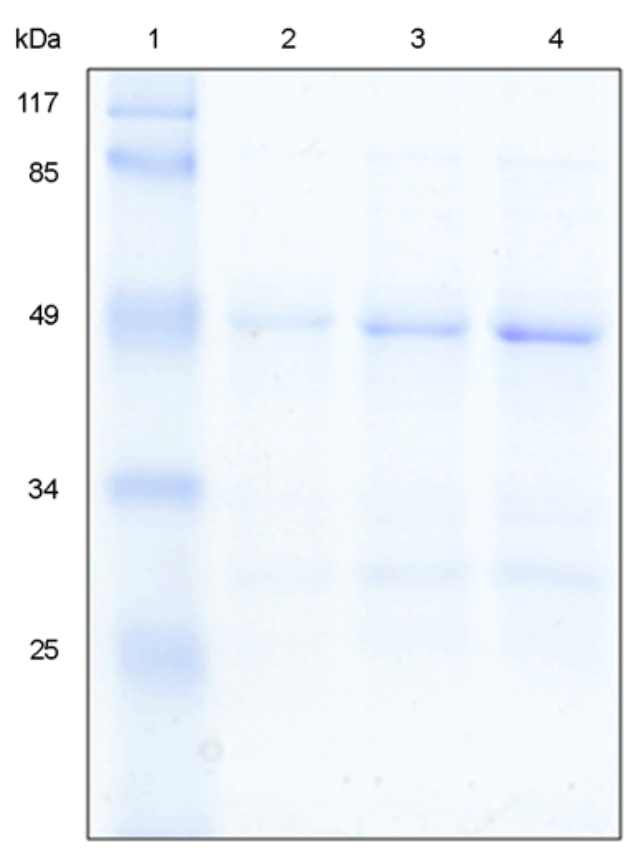

Figure 2. SDS-PAGE analysis of dialyzed Rv2041c protein. Purified Rv2041c fusion protein was dialyzed against PBS and then resolved by $12 \%$ SDS-PAGE. The protein bands were visualized by staining with Coomassie brilliant blue. Lane 1 is a molecular weight marker $(\mathrm{kDa})$. Lanes 2, 3, and 4 represent 2, 4, and $6 \mu \mathrm{g}$ dialyzed recombinant Rv2041c protein, respectively. hypoxic conditions. The transcriptional expression level of Rv2041c was compared to that of genes in the same operon and to genes belonging to the same functional group under the culture conditions described in MATERIALS AND METHODS. To determine Rv2041c expression at the transcriptional level at different conditions, mRNA of $M$. $t b$ H37Rv cultured in normal pH (7.2) or mildly acidic (6.0)

\section{(A)}

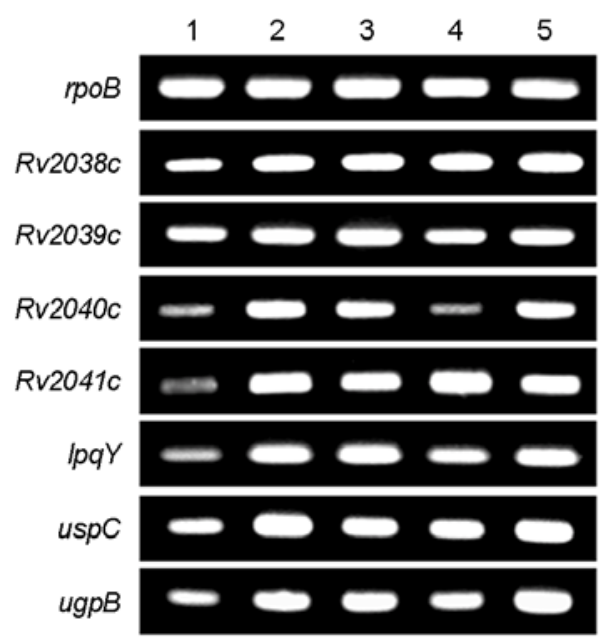

B

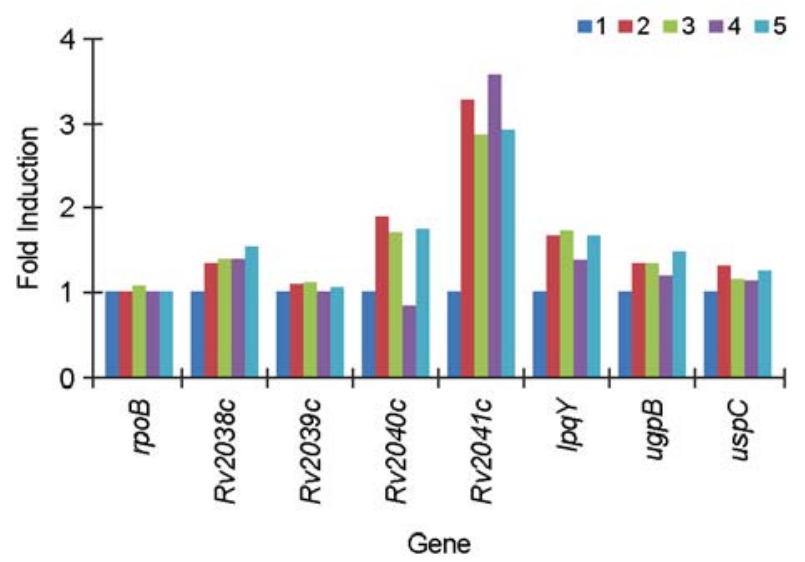

Figure 3. RT-PCR analysis of $R v 2038 c, R v 2039 c, R v 2040 c$, $R v 2041 c, l p q Y$, ugpB, and uspC in $M$. tb $\mathrm{H} 37 \mathrm{Rv}$ cultured under various conditions. The transcription level of each gene from $M$. $t b$ cultured at normal $(\mathrm{pH} 7.2)$ or acidic $(\mathrm{pH} 6.0)$ with hypoxic or anoxic conditions was measured by semi-quantitative RT-PCR (A). Based on the intensity of the bands, the results are expressed as fold-induction relative to the value for normal culture conditions (B). Lane 1, normal conditions (pH 7.2 and $21 \%$ oxygen tension); lane 2 , hypoxic condition ( $\mathrm{pH} 7.2$ and $13 \%$ oxygen tension); lane 3 , anoxic condition ( $\mathrm{pH} 7.2$ and $0 \%$ oxygen tension); lane 4 , mildly acidic and hypoxic condition (pH 6.0 and $13 \%$ oxygen tension); lane 5 , mildly acidic and anoxic condition $(\mathrm{pH} 6.0$ and $0 \%$ oxygen tension). 

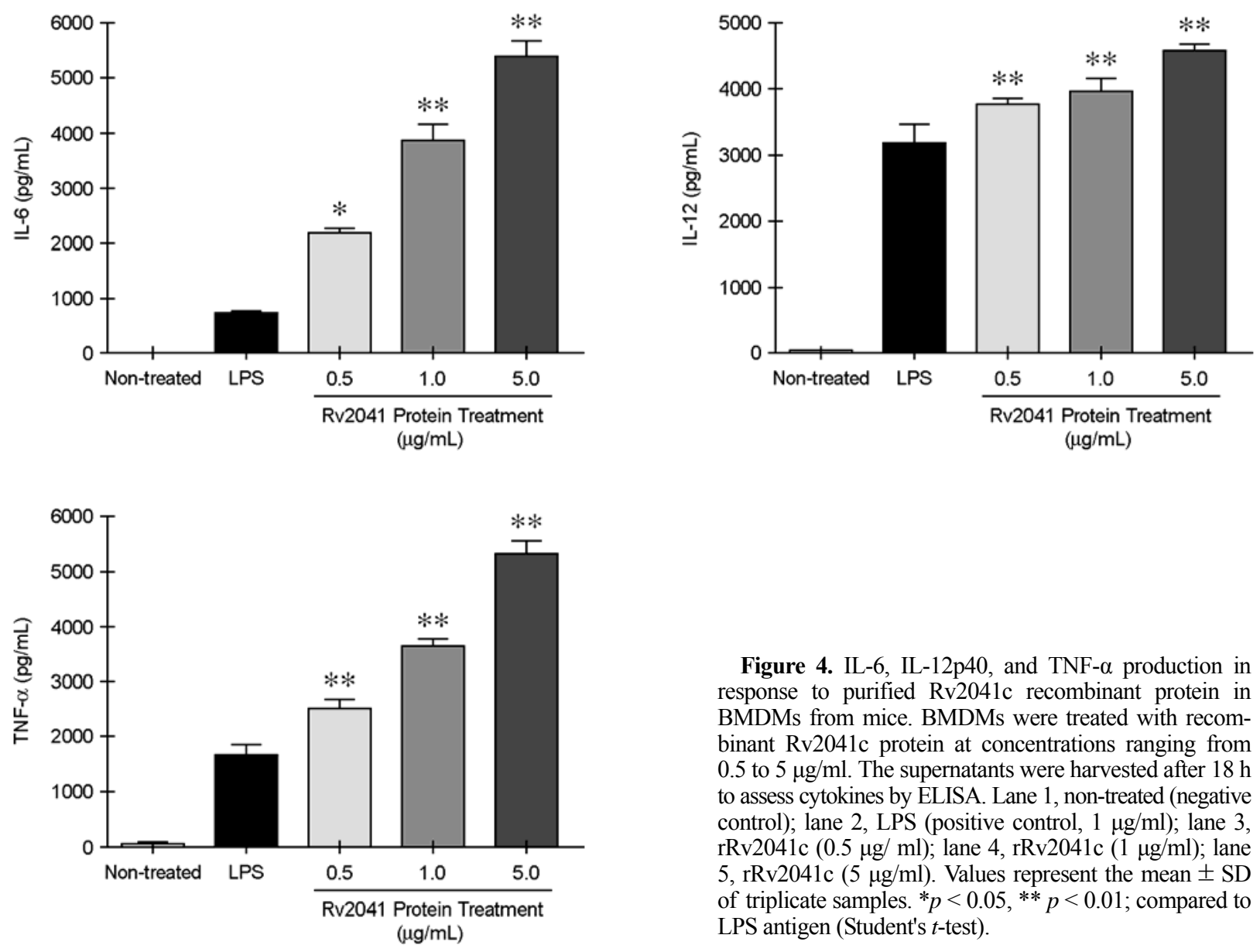

Figure 4. IL-6, IL-12p40, and TNF- $\alpha$ production in response to purified Rv2041c recombinant protein in BMDMs from mice. BMDMs were treated with recombinant Rv2041c protein at concentrations ranging from 0.5 to $5 \mu \mathrm{g} / \mathrm{ml}$. The supernatants were harvested after $18 \mathrm{~h}$ to assess cytokines by ELISA. Lane 1, non-treated (negative control); lane 2, LPS (positive control, $1 \mu \mathrm{g} / \mathrm{ml}$ ); lane 3, rRv2041c $(0.5 \mu \mathrm{g} / \mathrm{ml})$; lane 4 , rRv2041c $(1 \mu \mathrm{g} / \mathrm{ml})$; lane 5 , rRv2041c $(5 \mu \mathrm{g} / \mathrm{ml})$. Values represent the mean $\pm \mathrm{SD}$ of triplicate samples. ${ }^{*} p<0.05, * * p<0.01$; compared to LPS antigen (Student's $t$-test).

media with hypoxic or anaerobic conditions was measured by semi-quantitative RT-PCR. Based on the intensity of the bands, the results were expressed as a fold-induction relative to the value for normal culture conditions $(\mathrm{pH} 7.2,21 \%$ oxygen tension). The results depicted in Fig. 3 revealed that four genes of the $R v 2038 c \sim R v 2041 c$ operon $(R v 2038 c$, $R v 2039 c, R v 2040 c$, and Rv2041c) were expressed during the lifecycle of $M$. $t b$. When altered by oxygen tension or $\mathrm{pH}$, the transcripts of Rv2041c increased significantly.

Also, other sugar-binding protein genes such as $\operatorname{lp} q Y$, $u g p B$, and $u s p C$ were expressed during the lifecycle of $M$. tb (Fig. 3). When altered by oxygen tension or $\mathrm{pH}$, the transcripts of Rv2041c increased; however, the transcripts of other sugar-binding protein genes showed no significant change.

\section{Cytokine production in murine BMDMs in response to $\operatorname{Rv2041c}$ protein}

Because macrophages play pivotal roles in mycobacterial infections by secreting pro-inflammatory cytokines to activate a variety of immune effector cells, cytokine production by stimulation with rRv2041c in macrophages was exploited.

The production of proinflammatory cytokines such as TNF- $\alpha$, IL-6, and IL-12 during $M$. $t b$ infection is essential for the activation of effector cells for innate resistance (22 24). When BMDMs from mice were treated with varying concentrations $(0.5,1,5 \mu \mathrm{g} / \mathrm{ml})$ of purified rRv2041c for $18 \mathrm{~h}$, the secretion of TNF- $\alpha$, IL- 6 , and IL-12p40 in the culture medium increased significantly compared to those treated with $1 \mu \mathrm{g} / \mathrm{ml}$ LPS as a positive control (Fig. 4). Significant differences $(p<0.05 ; p<0.01)$ compared to 
LPS are depicted in Fig. 4.

IFN- $\gamma$ and TNF- $\alpha$ production in response to $\mathrm{Rv} 2041 \mathrm{c}$ in latent and active TB mice

Vaccination against $M$. $t b$ has been shown to require activated Th1 cells that induce the expression of Th1-type cytokines (e.g., IL-12, IFN- $\gamma$, TNF- $\alpha$ ). IFN- $\gamma$ and TNF- $\alpha$ are important macrophage activators produced by $\mathrm{T}$ cells when exposed to microbial products derived from $M$. $t b$ $(23,25)$. To analyze the cell-mediated responses of latent and active TB to the Rv2041c protein, lymphocytes of spleen from infected mice in a Cornell model were stimulated with purified rRv2041c protein, and then IFN- $\gamma$, and TNF- $\alpha$ production was measured by ELISA. A peak of IFN- $\gamma$ and TNF- $\alpha$ secretion was observed after 4 and 1 day(s) of stimulation, respectively. Thus, IFN- $\gamma$ and TNF- $\alpha$ concentration between latent and active TB mice were compared at 1 and 4 days. IFN- $\gamma$ responses at 4 days in both latent and active TB mice exceeded the responses from Con $\mathrm{A}$ as a positive control (Fig. 5; $p<0.01$ ). As shown in Fig. $5 \mathrm{~A}$ and $\mathrm{B}$, the spleen cells in active TB produced much higher levels of IFN- $\gamma$ than did the splenocytes in latent TB. And, TNF- $\alpha$ production at day 1 was also significantly induced by rRv2041c protein in latent and active TB mice (Fig. $5 ; p<0.01$ ). Similar to IFN- $\gamma$ secretion, splenocytes in active TB produced much higher levels of TNF- $\alpha$ than

\section{A}

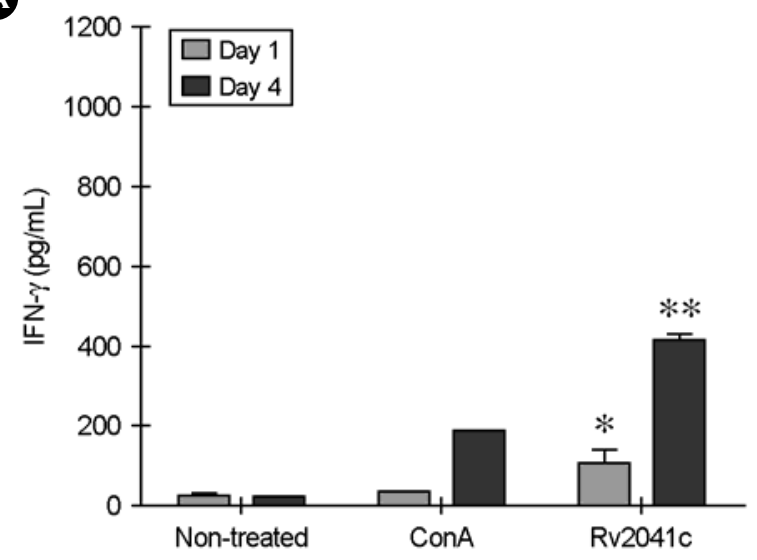

B
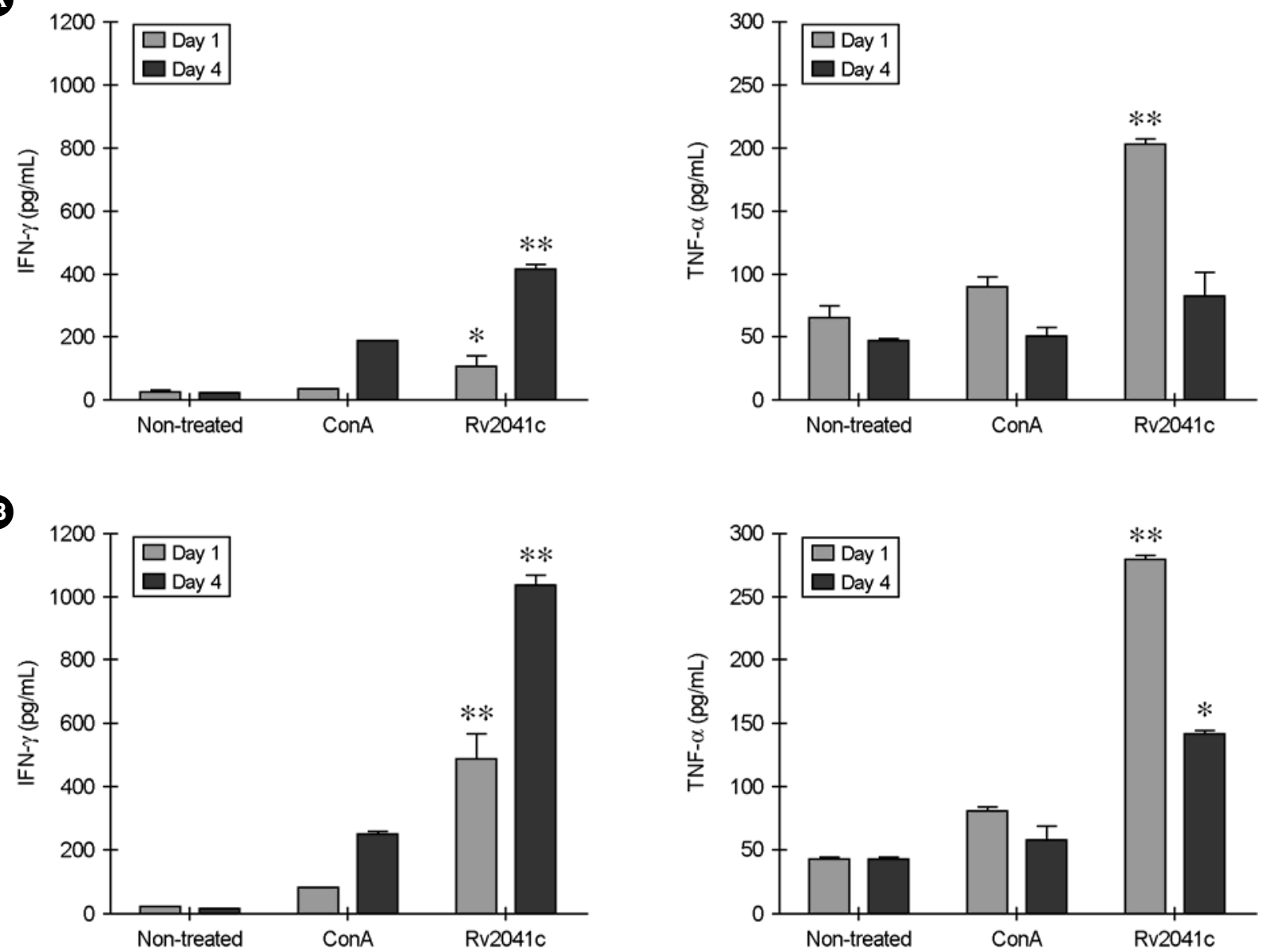

Figure 5. IFN- $\gamma$ and TNF- $\alpha$ production in response to purified Rv2041c recombinant protein in a latent and active TB model. The recombinant Rv2041c protein or Con A was used to treat lymphocytes of spleen from latent (A) and active (B) TB mice at a concentration of $10 \mu \mathrm{g} / \mathrm{ml}$. The supernatants were harvested after 1 (gray bar) or 4 days (black bar) to assess cytokines by ELISA. Non-treated and Con A-treated cells were used as negative and positive controls, respectively. Values represent the mean $\pm \mathrm{SD}$ of triplicate samples. ${ }^{*} p<0.05$, ${ }^{* *} p<0.01$; compared to the Con A antigen (Student's $t$-test). 
did splenocytes in latent TB. Therefore, the Rv2041c protein is a strong stimulator of IFN- $\gamma$ and TNF- $\alpha$ production.

\section{DISCUSSION}

Mycobacterial lipoproteins are crucial for synthesizing the unique mycobacterial cell envelope, the sensing of and protection from environmental stress, and participation in host-pathogen interactions (26). Due to their contribution to virulence, lipoproteins and the enzymes of the lipoprotein synthesis pathway represent promising drug targets. In addition, some lipoproteins confer a protective immune response and thus may qualify as subunit vaccines.

In a previous study, we verified the up-regulation of Rv2041c under hypoxic conditions and mildly acidic $\mathrm{pH}$ in M. $t b$ by DECAL. Rv2041c is expressed weakly in vitro under normal culture conditions $\left(\mathrm{pH} 7.2\right.$ and $21 \% \mathrm{O}_{2}$ pressure); however, a high level of Rv2041c expression was induced when $M$. $t b$ was cultivated at low $\mathrm{pH}$ under hypoxic conditions that mimic in vitro inside macrophages (12). The purpose of this study was to investigate the significant induction of Rv2041c transcripts in $M$. $t b$ growing in vitro, as well as assess its immunostimulatory capabilities in macrophages and in vivo TB model.

First, we successfully expressed and purified the recombinant Rv2041c protein in an E. coli system. The availability of sufficient amounts of Rv2041c is an essential part of studying the immunological characters of the protein.

Next, we confirmed that Rv2041c was induced under mild acidic and hypoxic conditions (in contrast to other genes included in the Rv2038 Rv2041 operon, which is an $\mathrm{ABC}$ transporter for an undetermined sugar) and that the other three SBP genes were involved in the sugar transporter of $M$. $t b$ by semi-quantitative RT-PCR. As shown in Fig. 3, Rv2041c was up-regulated significantly. A possible role for $R v 2041 c$ is that it may be important for the maintenance of intracellular survival during infection (12).

The rRv2041c induced pro-inflammatory cytokines such as IL-6 and IL-12p40 in murine BMDMs in a dosedependent manner. It has been known that mycobacterial lipoproteins recognized by TLR2 on macrophages can activate innate immune responses such as TNF- $\alpha$ and IL-12 production $(27,28)$. IL-6 has been associated with protection against $M$. $t b$ with a role in granuloma maintenance. It is clear that the maintenance of granulomas requires antigenspecific T cells (22). IL-6 acts as a regulator of the T cell responses that are critical for the maintenance of granulomas, especially during infection. IL-6 was higher in TB patients than in healthy controls (29). In addition, IL-12 has been shown to be crucial in the development of protective immunity against TB, and in the maintenance of latency. Persistent IL-12 production is necessary for the maintenance of Th1-dependent host resistance to $M$. $t b$ (24). This is important in vaccine design.

Rv2041c protein can increase IL-6 and IL-12p40 secretions in macrophages, suggesting that Rv2041c protein can induce the protective immune response. The proinflammatory cytokines are essential to the activation of the anti-mycobacterial activity of macrophages and T lymphocytes. Therefore, $\mathrm{rRv} 2041 \mathrm{c}$ might be used as a vaccine or diagnostic candidate antigen.

In the present study, we also demonstrated increased IFN- $\gamma$ and TNF- $\alpha$ production in rRv2041c stimulated splenocytes from active TB mice compared to latent TB mice. IFN- $\gamma$ and TNF- $\alpha$ response by splenocytes from $M$. $t b$-infected mice exceeded the responses from the Con $\mathrm{A}$ control. Therefore, rRv2041c acts as a stimulator of IFN- $\gamma$ and TNF- $\alpha$ production. It is well established that Th1 cytokines, in particular IFN- $\gamma$ and TNF- $\alpha$, are important in the control of $M$. $t b$ infection $(23,25)$. IFN- $\gamma$ produced by $\mathrm{T}$ cells and NK cells stimulates a mycobactericidal response in macrophages characterized by the induction of nitric oxide synthase (NOS). In synergy with IFN- $\gamma$, TNF- $\alpha$ activates macrophages to kill intracellularly replicating $M$. $t b$ (30). During the early stages of mycobacterial infection, macrophages and $\mathrm{T}$ cells actively interact to control the infection. TB patients generally had higher production of cytokines such as IFN- $\gamma$ and TNF- $\alpha$ than controls and this was observed in both of the CD4+ and CD8+ T cell subsets (31). Recent evidence suggests that TB disease is associated with an increase in proportion of $\mathrm{T}$ lymphocytes capable of producing TNF- $\alpha$ in combination with IFN- $\gamma$. It seems 
reasonable that IFN- $\gamma$ and TNF- $\alpha$ was more elevated in active TB mice compared to latent TB mice in this study. Our data indicate that an increased pattern of cytokine production against TB antigen between latent and active TB may be associated with an increased proportion of IFN- $\gamma$ and TNF- $\alpha$ producing cells in active TB disease progression.

Proteins are covalently modified with lipids via multiple mechanisms in the cytoplasm or on the cytoplasmic face of membranes and protein lipidation affects the function and location of proteins $(32,33)$. The rRv2041c protein was amplified from E. coli. The lipidation of rRv2041c protein may be different from protein produced from $M$. $t b$. Maybe the innate immune responses induced by non-lipidated protein can be different from lipidated protein.

In summary, the Rv2041c protein is thought to be important for the maintenance of intracellular survival during infection (12). In addition, rRv2041c induces a host protective immune response with ex vivo stimulation of mouse. The rational development of an effective subunit vaccine requires the identification of candidate antigens of $M$. $t b$ and a protective immune response in the host-pathogen interaction. We identified Rv2041c of $M$. $t b$ for intracellular survival in a previous study and have characterized the immunoreactivity of Rv2041c in this study. Therefore, Rv2041c may be a candidate anti-TB vaccine in the future.

\section{REFERENCES}

1) Harries AD, Dye C. Tuberculosis. Ann Trop Med Parasitol 2006;100:415-31.

2) Flynn JL, Chan J. Immunology of tuberculosis. Annu Rev Immunol 2001;19:93-129.

3) Young DB, Perkins MD, Duncan K, Barry CE, 3rd. Confronting the scientific obstacles to global control of tuberculosis. J Clin Invest 2008;118:1255-65.

4) Dietrich J, Doherty TM. Interaction of Mycobacterium tuberculosis with the host: consequences for vaccine development. APMIS 2009;117:440-57.

5) Leung CC, Tam CM, Chan SL, Chan-Yeung M, Chan CK, Chang KC. Efficacy of the BCG revaccination programme in a cohort given $\mathrm{BCG}$ vaccination at birth in Hong Kong. Int J Tuberc Lung Dis 2001;5:717-23.

6) Rodrigues LC, Pereira SM, Cunha SS, Genser B, Ichihara MY, de Brito SC, Hijjar MA, Dourado I, Cruz AA, Sant'Anna C, Bierrenbach AL, Barreto ML. Effect of $\mathrm{BCG}$ revaccination on incidence of tuberculosis in school-aged children in Brazil: the BCG-REVAC cluster-randomised trial. Lancet 2005;366:1290-5.

7) Brandt L, Feino Cunha J, Weinreich Olsen A, Chilima B, Hirsch P, Appelberg R, Andersen P. Failure of the Mycobacterium bovis BCG vaccine: some species of environmental mycobacteria block multiplication of $\mathrm{BCG}$ and induction of protective immunity to tuberculosis. Infect Immun 2002;70:672-8.

8) Sable SB, Plikaytis BB, Shinnick TM. Tuberculosis subunit vaccine development: impact of physicochemical properties of mycobacterial test antigens. Vaccine 2007;25:1553-66.

9) Fontan P, Aris V, Ghanny S, Soteropoulos P, Smith I. Global transcriptional profile of Mycobacterium tuberculosis during THP-1 human macrophage infection. Infect Immun 2008;76:717-25.

10) Monahan IM, Betts J, Banerjee DK, Butcher PD. Differential expression of mycobacterial proteins following phagocytosis by macrophages. Microbiology 2001;147:459-71.

11) Voskuil MI, Visconti KC, Schoolnik GK. Mycobacterium tuberculosis gene expression during adaptation to stationary phase and low-oxygen dormancy. Tuberculosis (Edinb) 2004;84:218-27.

12) Kim SY, Lee BS, Shin SJ, Kim HJ, Park JK. Differentially expressed genes in Mycobacterium tuberculosis H37Rv under mild acidic and hypoxic conditions. J Med Microbiol 2008;57:1473-80.

13) Braibant M, Gilot P, Content J. The ATP binding cassette $(\mathrm{ABC})$ transport systems of Mycobacterium tuberculosis. FEMS Microbiol Rev 2000;24:449-67.

14) Sutcliffe IC, Harrington DJ. Lipoproteins of Mycobacterium tuberculosis: an abundant and functionally diverse class of cell envelope components. FEMS Microbiol Rev 2004;28:645-59.

15) Sampaio EP, Elloumi HZ, Zelazny A, Ding L, Paulson ML, Sher A, Bafica AL, Shea YR, Holland SM. Mycobacterium abscessus and M. avium trigger Tolllike receptor 2 and distinct cytokine response in human 
cells. Am J Respir Cell Mol Biol 2008;39:431-9.

16) Beggs WH, Jenne JW. Mechanism for the pyridoxal neutralization of isoniazid action of Mycobacterium tuberculosis. J Bacteriol 1967;94:793-7.

17) Payton M, Pinter K. A rapid novel method for the extraction of RNA from wild-type and genetically modified kanamycin resistant mycobacteria. FEMS Microbiol Lett 1999;180:141-6.

18) Kaushik RS, Uzonna JE, Zhang Y, Gordon JR, Tabel H. Innate resistance to experimental African trypanosomiasis: differences in cytokine (TNF-alpha, IL-6, IL-10 and IL-12) production by bone marrow-derived macrophages from resistant and susceptible mice. Cytokine 2000;12:1024-34.

19) Yang CS, Lee DS, Song CH, An SJ, Li S, Kim JM, Kim CS, Yoo DG, Jeon BH, Yang HY, Lee TH, Lee ZW, El-Benna J, Yu DY, Jo EK. Roles of peroxiredoxin II in the regulation of proinflammatory responses to LPS and protection against endotoxin-induced lethal shock. J Exp Med 2007;204:583-94.

20) Ha SJ, Jeon BY, Kim SC, Kim DJ, Song MK, Sung YC, Cho SN. Therapeutic effect of DNA vaccines combined with chemotherapy in a latent infection model after aerosol infection of mice with Mycobacterium tuberculosis. Gene Ther 2003;10:1592-9.

21) Ha SJ, Jeon BY, Youn JI, Kim SC, Cho SN, Sung YC. Protective effect of DNA vaccine during chemotherapy on reactivation and reinfection of Mycobacterium tuberculosis. Gene Ther 2005;12:634-8.

22) Dannenberg AM, Jr. Delayed-type hypersensitivity and cell-mediated immunity in the pathogenesis of tuberculosis. Immunol Today 1991;12:228-33.

23) Flynn JL, Goldstein MM, Chan J, Triebold KJ, Pfeffer K, Lowenstein CJ, Schreiber R, Mak TW, Bloom BR. Tumor necrosis factor-alpha is required in the protective immune response against Mycobacterium tuberculosis in mice. Immunity 1995;2:561-72.

24) Trinchieri G. Interleukin-12 and the regulation of innate resistance and adaptive immunity. Nat Rev Immunol 2003;3:133-46.

25) Flynn JL, Chan J, Triebold KJ, Dalton DK, Stewart TA, Bloom BR. An essential role for interferon gamma in resistance to Mycobacterium tuberculosis infection. J Exp Med 1993;178:2249-54.

26) Rezwan M, Grau T, Tschumi A, Sander P. Lipoprotein synthesis in mycobacteria. Microbiology 2007;153:652 -8 .

27) Jo EK, Yang CS, Choi CH, Harding CV. Intracellular signalling cascades regulating innate immune responses to Mycobacteria: branching out from Toll-like receptors. Cell Microbiol 2007;9:1087-98.

28) Jung SB, Yang CS, Lee JS, Shin AR, Jung SS, Son JW, Harding CV, Kim HJ, Park JK, Paik TH, Song CH, Jo EK. The mycobacterial 38-kilodalton glycolipoprotein antigen activates the mitogen-activated protein kinase pathway and release of proinflammatory cytokines through Toll-like receptors 2 and 4 in human monocytes. Infect Immun 2006;74:2686-96.

29) Ellertsen LK, Storla DG, Diep LM, Brokstad KA, Wiker HG, Hetland G. Allergic sensitisation in tuberculosis patients at the time of diagnosis and following chemotherapy. BMC Infect Dis 2009;9:100.

30) Chakravarty SD, Zhu G, Tsai MC, Mohan VP, Marino S, Kirschner DE, Huang L, Flynn J, Chan J. Tumor necrosis factor blockade in chronic murine tuberculosis enhances granulomatous inflammation and disorganizes granulomas in the lungs. Infect Immun 2008;76:916-26.

31) Sutherland JS, Adetifa IM, Hill PC, Adegbola RA, Ota MO. Pattern and diversity of cytokine production differentiates between Mycobacterium tuberculosis infection and disease. Eur J Immunol 2009;39:723-9.

32) Bhatnagar RS, Gordon JI. Understanding covalent modifications of proteins by lipids: where cell biology and biophysics mingle. Trends Cell Biol 1997;7:14-20.

33) Nadolski MJ, Linder ME. Protein lipidation. FEBS J 2007;274:5202-10. 